20. Кострикова Е.Г. Внешняя политика в общественном мнении России накануне Первой мировой войны. 1908-1914 гг.: дис. ... д-ра ист. наук. М., $2011.473 \mathrm{c}$

21. АВПРИ. Ф. ДЛС и ХД. Оп. 731. Д. 27.

\section{N.V. CHARYKOV'S ACTIVITIES ON REFORMING THE MINISTRY OF FOREIGN AFFAIRS OF RUSSIA}

(C) 2016

O.A. Chernov, candidate of history sciences, Associate Professor of Domestic history and archeology

Abstract. The problem of reforming the Ministry of Foreign Affairs of the Russian Empire in the beginning of XX century was widely highlighted in historical literature. However, the role of N.V. Charykov is covered very briefly. Since he was the chairman of the council on the reform of the Ministry of Foreign Affairs, it seemed necessary to explore his ideas and role in this transformative direction. He became the head of the council on the reform of the Ministry of Foreign Affairs after he had an appointment to a deputy minister of Foreign Affairs. It happened after A.P. Izvolsky (N.V. Charykov's friend and classmate at Imperial Alexander Lyceum) had become a foreign minister. N.V. Charykov denotes that A.P. Izvolsky invited him to become the deputy minister of Foreign Affairs. All the legal affairs of the Ministry of Foreign Affairs were transferred under authority of N.V. Charykov by A.P. Izvolsky.

N.V. Charykov took up his post as the deputy minister of Foreign Affairs and was the head of the council on the reform of the Ministry of Foreign Affairs, implemented thoughtful and meticulous work. He could establish coordination among the actions of all the departments from which the reform was dependent on. Furthermore, he believed in the necessity of changing the structure of the Ministry of Foreign Affairs, linking it to the need to increase funding. Besides, he stood out for maintaining diplomatic correspondence in Russian instead of French. The important point was a democratization of the diplomatic exam on the one hand and an increase of the level of educational requirements for candidates on the other.

Keywords: N.V. Charykov; A.P. Izvolsky; M.A. Taube; K.N. Gubastov; G.N. Mihajlovsky; I.A. Persiani; S.M. Gorjainov; V.O. von Clemm; G.A. Planson; M.I. Muromtsev; Yu.Ya. Solov'ev; K.K. Buksgevden; A.K. Bentkovsky; Alexander imperial lyceum; reform; Ministry for Foreign Affairs; foreign policy of Russia; Russian diplomacy.

УДК 94(470.56)+37.014.22(091)

\section{ОБРАЗОВАТЕЛЬНАЯ И КУЛЬТУРНО-ПРОСВЕТИТЕЛЬНАЯ РАБОТА В КРАСНОЙ АРМИИ В 1920-1930-Е ГОДЫ: НА МАТЕРИАЛАХ ОРЕНБУРЖЬЯ}

(C) 2016
Л.В. Петрич, кандидат исторических наук, доцент кафедры истории России Оренбургский государственный педагогический университет, Оренбург (Россия)

Аннотащия. В статье освящается важный аспект в ликвидации неграмотности в годы Советской власти обучение красноармейцев и допризывников. От состояния грамотности данной категории населения в немалой степени зависела боеспособность Красной Армии. Проанализировав научную историческую литературу по данной теме, сделан вывод, что рассматриваемая тема изучена на сегодняшний день недостаточно. Отмечено, что во всей своей полноте проблема улучшения боевой подготовки Красной Армии встала в 1923 г., когда она перешла на мирное положение. В это же время был разработан декрет ВЦИК и СНК о привлечении к обязательным занятиям по ликвидации неграмотности всех допризывников во время прохождения ими допризывной военной подготовки. В работе выявлено, что в конце 1920 - начале 1930-х гг. работа по обучению красноармейцев и допризывников была продолжена во время культпоходов. Указано, что при организации обучения значительное внимание уделялось содержанию образовательного материала, связанного с политическим просвещением военнослужащих. Отмечены особенности, трудности и недостатки при организации работы с личным составом Красной Армии в Оренбуржье: низкая посещаемость ликпунктов, большой отсев из них. В статье сделан вывод, что система ликвидация неграмотности в тяжелые военные годы доказала свою крайнюю жизненную важность и необходимость в деле прямой защиты, укрепления и строительства государства. Это явилась важным фактором победы в Великой Отечественной войне.

Ключевые слова: ликвидация неграмотности; красноармейцы; допризывники; новобранцы; Красная Армия; неграмотные; малограмотные; воспитательная работа; политические занятия; культпоход; ликпункты; военнослужащие; образовательный уровень; политические отделы; комиссии по ликвидации неграмотности; культурно-просветительная работа; Оренбуржье.

В начале XXI века стало ясно, что последствия внутриполитического и экономического кризиса начала 1990-х гг. привели к усилению бездуховности, падению образовательного и культурного уровня будущих защитников Родины. К сложно- стям внутреннего порядка, характерным для движения России по пути радикальной модернизации, добавились трудности, обусловленные ростом международной напряженности, в частности, терроризмом. 
В современной обстановке задачи повышения уровня военной безопасности и укрепления обороноспособности Отечества встали с особой остротой, значительно возросла значимость образовательной и воспитательной работы среди личного состава Вооруженных сил. Данное обстоятельство показывает, что настоящая статья, посвященная обобщению исторического опыта образовательной работы органов государственной власти и военного управления в Красной армии в 1920-1930-х гг., выполнена на актуальную тему.

В научной исторической литературе нашли отражения различные аспекты обучения красноармейцев. В ряде трудов была показана ликвидация неграмотности как в общем аспекте культурно-просветительной работы и ее роль в формировании у воинов морально-политических и боевых качеств $[1 ; 2,3 ; 4]$. В некоторых изданиях освящались конкретные проблемы обучения красноармейцев и допризывников [5]. Вопросы ликвидации безграмотности красноармейцев в период перевода РККА на мирное положение были рассмотрены и в монографии В.А. Куманева [6]. В статье В.Ф. Клочкова рассмотрены не только задачи, формы, средства и методы «коммунистического воспитания», но и достаточно полно раскрыты основные направления ликвидации неграмотности в РККА [7].

На современном этапе наиболее полно, по сравнению с указанными ранее исследованиями, тема раскрыта в диссертации Н.Я. Елисеевой [8], посвященной анализу просветительной деятельности советской власти в РККА в 1918-1920 гг.

В своей монографии Т.В. Филоненко обращается внимание, что в 1920-1930-х гг. ликвидацию неграмотности велась, прежде всего, среди организованных групп населения, а особое внимание в данном вопросе отводилось грамотности в армии и на флоте [9].

Из современных исследований следует отметить кандидатскую диссертацию О.Н. Поповой [10], которая в своем исследовании уделила ликвидации неграмотности отдельный параграф, отметив политизированный характер данной деятельности.

Среди региональной литературы по данной проблеме следует отметить работы Н.И. Сайгина, который в своих работах отмечал, что Коммунистическая партия при ликвидации неграмотности среди красноармейцев ставила целью не столько их обучение, сколько поднять в школах грамотности их политическое сознание $[11 ; 12]$.

Анализ историографической ситуации позволяет сделать вывод о том, что рассматриваемая тема изучена на сегодняшний день недостаточно. Более детально в научной литературе отображена деятельность органов государственной власти и военного управления по строительству вооруженных сил, проведению партийно-политической работы. Несмотря на имеющиеся исследования по отдельным направлениям культурно-просветительной работы (ликвидация безграмотности, профессиональная подготовка личного состава), до сих пор нет специального исследования всех направлений. Цель данной статьи раскрыть особенности образовательной и культурнопросветительной работы среди красноармейцев в Оренбуржье в 20-30-е годы XX века.

Образовательный уровень как новобранцев, так и рядового состава, зависел от общей линии «культур- ной революции» на ликвидацию неграмотности, и повышения уровня образования. Несомненно, рост технической оснащенности вооруженных сил предъявлял и более высокие требования к общему и специальному образовательному уровню военнослужащих, причем не только командного состава.

В начале 1920-х гг. наиболее полно учет неграмотного населения велся среди организованных групп населения, в т.ч. среди красноармейцев. Обучение красноармейцев началось еще во время Гражданской войны. Красноармейцы, подлежавшие обучению, объединялись в отдельные команды и в служебном порядке обучались грамоте, частично освобождаясь от караульной службы. Грамоте обучались не только в тыловых частях, но и на фронте, в перерывах между боями.

15 сентября 1920 г. вышел приказ Военного совета № 396 по войскам Оренбургского укрепленного района, в котором всем частям приказывалось немедленно организовать комиссии по ликвидации неграмотности [13, л. 1-1 об.]. Все неграмотные, не посещающие школы, согласно этому приказу подвергались дисциплинарному взысканию как за нежелание выполнять строевые обязанности. При политических отделах укрепленных пунктов создавались комиссии по ликвидации неграмотности, которые следили за работой по ликвидации неграмотности в войсковых частях: брали на учет всех неграмотных, вели агитацию и пропаганду за грамотность, устраивали недели «Борьбы с неграмотностью красноармейцев» и др. Каждый неграмотный красноармеец обучался до тех пор, пока комиссия не удостоверялась в его грамотности [13, л. 2-4].

Всего за 1920 г. в Красной Армии было обучено 107645 человек. Особенно напряженно пошла работа после издания приказа от 28 февраля 1922 г. за № 515, которым устанавливался окончательный срок ликвидации неграмотности в Красной Армии - 1 мая 1922 г. В результате за 1922 г. было обучено еще 78995 человек [14, с. 50-51].

Данный вопрос обсуждался на I Всероссийском съезде по ликвидации неграмотности (февраль 1922 г.). Съезд признал необходимым обучить в первую очередь людей в возрасте от 18 до 30 лет и обеспечить полную ликвидацию неграмотности в Красной Армии (включая и новые призывные возрасты).

Во всей своей полноте проблема улучшения боевой подготовки Красной Армии встала в 1923 г., когда она перешла на мирное положение. В этих условиях со всей очевидностью встал вопрос о ликвидации неграмотности среди допризывников. В это же время был разработан декрет ВЦИК и СНК о привлечении к обязательным занятиям по ликвидации неграмотности всех допризывников во время прохождения ими допризывной военной подготовки $[15$, л. 50].

На заседании коллегии агитационно-пропагандистского отдела Оренбургского губернского комитета РКП (б) от 12 декабря 1923 г. отмечалось, что ликвидации неграмотности среди красноармейцев проходит успешно, 100 красноармейцев посещают школы [16, л. 22]. В 1924 г. работа в Оренбургской губернии продолжалась среди демобилизованных красноармейцев [17, л. 48].

Реввоенсовет Республики с Главполитпросветом разработал план ускоренного обучения допризывников, чтобы обеспечить Красной Армии грамотное 
Петрич Л.В.

Образовательная и культурно-просветительная работа в Красной Армии..

07.00.00 - исторические науки и археология

пополнение. Ввиду особой важности этой задачи ВЦИК отпустил специальные ассигнования на учебные пособия для призывников. Остальные расходы на обучение допризывников были отнесены на местные средства [18, с. 134]. В эти годы был разработан специальный «Букварь красноармейца», по которому велись занятия в Красной Армии и среди допризывников.

В 1924 г. во время осенних сборов допризывников 1903 года рождения в Оренбургском уезде было выявлено 44\% малограмотных и $8 \%$ неграмотных. Они были прикреплены к ликпунктам, где проходили обучение в течение полутора месяцев [19, л. 24-27]. Занятия проводились ежедневно комплексным методом квалифицированными преподавателями [19, л. 5].

В докладе о работе политорганов Приволжского военного округа 1925 г. были отмечены определенные трудности при обучении красноармейцев: слабая подготовка учителей, как в методическом, так и в политическом отношениях, нерегулярное посещение занятий из-за перегруженности красноармейцев. В указанное время обучалось 19 групп, куда входил 381 неграмотный красноармеец. Большую помощь оказывал профсоюз работников просвещения, выступающий культшефом данной работы. Стоит отметить, что занятия организовывались и на родном языке для национальных меньшинств (немцы и мордва) [20, л. 54 об.].

В конце 1920 - начале 1930-х гг. работа по обучению красноармейцев и допризывников была продолжена во время культпоходов. В постановлении ЦК ВКП(б) от 17 мая 1929 г. «О работе по ликвидации неграмотности» ЦК предлагал партийным, советским и профессиональным организациям в первую очередь охватывать системой ликвидации неграмотности «в городе - индустриальных рабочих и новые слои пролетариата, в деревне - батрачество, рабочих совхозов, сезонников, бедноту, членов колхозов» [21, с. 268].

В середине 1930-х годов работе по обучению и воспитанию допризывников уделялось большое внимание. В 1935 г. вышло Постановление Президиума Оренбургского областного исполнительного комитета «О подготовке к призыву граждан 1913 года рождения». В Постановлении отмечалась необходимость уделить общеобразовательной подготовке допризывников не менее двух часов в день. Областным организациям предписывалось обратить внимание на материальное и политпросветительное обеспечение учебных пунктов [22, л. 1].

С 1 июля 1935 года были открыты пункты для неграмотных и малограмотных допризывников с отрывом от производства. Качество обучения на данных курсах обеспечивалось тем, что преподавали здесь исключительно «платные» учителя. Заведующий районным отделом народного образования и военные инспектора организовывали систематический контроль за ходом обучения. Особое внимание обращалось на качество обучения и 100\%-ю посещаемость [22, л. 3].

Во второй половине 1930-х гг. страны «антикоминтерновского пакта» (Германия, Италия, Япония) развернули активную подготовку к войне за новый передел мира. Нарастала угроза нового мирового конфликта. Военная опасность поставила задачу максимального укрепления обороноспособности страны.
В постановлении ЦК ВКП(б) и СНК СССР «О работе по обучению неграмотных и малограмотных» от 27 февраля 1936 г. говорилось о такой организации обучения допризывников, «чтобы с 1936 г. среди призывающихся в Красную Армию не было ни одного неграмотного и малограмотного» [23, с. 387]. После XVIII съезда ВКП(б) (март 1939 г.), который ставил задачей всемерное повышение обороноспособности страны, стало уделяться исключительное внимание оборонно-массовой работе, укреплению материальной базы Осоавиахима, физкультурных обществ. Вопросы оборонно-массовой работы среди трудящихся обсуждались на съездах компартий союзных республик, краевых, областных, районных и городских партийных конференциях, на партийных активах, пленумах и бюро партийных комитетов. Широкое распространение получило соревнование среди Советов, колхозов и предприятий по подготовке к обороне страны, особенно в обучении допризывников, по успешному проведению призывов молодежи в армию.

Пропагандировались боевые подвиги воинов Советской Армии и Флота, особенно героизм и мужество советских добровольцев, сражавшихся против агрессоров в Испании и Китае, а также участников боев у озера Хасан и на реке Халхин-Гол.

Приковывалось внимание советских граждан к работе массовых оборонных организаций - Ocoавиахима, общества Красного Креста и Красного Полумесяца. С их участием на предприятиях, в учреждениях, колхозах, совхозах, МТС проводились так называемые оборонные дни, дававшие трудящимся определенную сумму военных знаний. Большую работу по интернациональному воспитанию советского народа проводила Международная организация помощи борцам революции (МОПР) [24, с. 131].

Советской власти нужны были сознательные защитники Отечества. Красноармеец должен был понимать не только свои служебные обязанности, но и знать, за что борется, знать, что такое Советская власть, почему нужен союз и братское единение с пролетариатом всего мира, как устроено советское государство, какую работу ведет Советская власть в области народного хозяйства. Красноармеец должен был быть грамотным, уметь читать книжку, газету, уметь написать письмо домой, рапорт по службе. Красноармеец-крестьянин должен был получить сведения о том, как лучше вести сельское хозяйство и т.П. [25].

Большое значение наряду с обучением грамоте имели политические занятия, которые велись политическими отделами. В серии пособий политрукам к политуставу говорилось, что «красноармеец должен знать, какие враги есть у Советской Республики, как идут дела у нас в стране, ибо красноармеец - лучший политик, и чем крепче он держит винтовку, чем тверже стоит он на своем посту, тем мягче разговаривают с нами иностранные капиталисты, тем спокойнее и успешнее работают трудящиеся по хозяйству. Советская власть в своей политике опирается на широкие народные массы, на всю Красную армию, и поддержка трудящихся в политике - ее лучшее оружие» [26, с. 219].

С этой же целью во всех полках и частях были организованы клубы, при клубах организовывались 
кружки, в которых красноармейцы могли получить знания по политическим, военным, сельскохозяйственным, техническим и иным вопросам.

Л.Д. Троцкий писал, что: «самое главное - побороть в армии духовную вшивость (безграмотность) и физическую. Нужно добиться того, чтобы красноармеец был опрятен, чист, аккуратен, чтобы он был бережливым и хозяйственным человеком. С этой целью в армии ведется работа по хозяйственному воспитанию и санитарному просвещению» [25].

Бюро Оренбургского областного комитета ВКП(б) в марте 1936 г., обсудив постановлении ЦК ВКП(б) и СНК СССР «О работе по обучению неграмотных и малограмотных» от 27 февраля 1936 г. определило порядок обучения допризывников. Обучать грамоте допризывников было решено с отрывом от производства, в специальных межрайонных и районных школах в течение полутора месяцев. Время обучения в этих школах засчитывалось для сельских жителей в виде трудодней, а за рабочими сохранялась средняя заработная плата [27, л. 15]. Во время страды Оренбургский областной комитет ВКП(б) предложил организовать обучение допризывников следующим образом: культармейцы прикреплялись к допризывникам, организуя обучения прямо в поле, на рабочем месте [28, л. 44].

Однако на деле обучение допризывников шло не так гладко. В Соль-Илецком районе в 1936 году из 118 допризывников обучалось только 78 человек. Обучение допризывников велось нерегулярно, часто не доводилось до конца [29, л. 12]. В мае 1937 г. выяснилось, что из 366 допризывников вышеназванного района неграмотными и малограмотными оказались 159 человек, или 43\% всего состава. Это произошло потому, что учителя определяли грамотными тех людей, которые на самом деле являлись малограмотными [30, л. 17].

Особым постановлением Оренбургского обкома ВКП(б) от 13 июля 1936 г. «О ходе обучения неграмотных и малограмотных допризывников рождения 1914-1915 гг.» отмечалось неудовлетворительное положение дел: «...из учтенных 1504 неграмотных... обучено только 791 человек, обучается 624 и совершенно не охвачено учебой 89 человек, из учтенных 7181 малограмотного обучено 2460 человек, обучается 3349 и совершенно не охвачено учебой 1372 человека...» [31, л. 54-55]. На заседании бюро Оренбургского обкома ВКП(б) 13 января 1937 г. райисполкомы и райкомы ВКП(б) обязывались организовать обучение всех неграмотных допризывников с отрывом от производства с сохранением зарплаты и трудодней колхозникам [32, л. 81-82].

Главное управление Рабоче-Крестьянской Красной Армии специальными инструкциями регламентировало работу по обучению допризывников. Все допризывники, учтенные военными комиссариатами, делились по уровню грамотности на 4 группы. Специальные комиссии при военкомате, состоящие из школьных учителей, выявляли степень грамотности и ставили особую отметку в военном билете, после чего зачисляли молодежь на специальные курсы или в школы допризывников. Контроль над посещением занятий и дисциплиной осуществляли военкоматы, а обеспечение литературой, методическими пособия- ми, бумагой и проч., а также направление туда учителей - городские и районные органы народного образования. В сельских областях Оренбургской области к работе с неграмотными допризывниками привлекались культармейцы, мобилизованные комсомольскими организациями. Допризывников объединяли в группы и ежедневно занимались с ними по 24 часа на призывном пункте.

Стимулом в учебе для допризывника служила надежда попасть в военное учебное заведение, так как во время набора вербовочная комиссия красочно описывала жизнь военнослужащего [33, с. 279]. Для сельского юноши 18-20 лет попасть в военное училище означало решение всех жизненных вопросов, тем более что для набора в вышеназванные училища предпочтение отдавалось представителям рабочих и бедных крестьян. Следовательно, набор на учебу в военные училища в какой-то мере содействовал ликвидации неграмотности среди допризывников [24, c. 132].

К концу 30-х гг. ХХ в. улучшилась подготовка призывников к воинской службе, их отбор и распределение, обучение первоначальным навыкам военного дела. С ними проводилась большая воспитательная работа. Призывники изучали решения партии и правительства, особенности строительства Советской Армии, основные положения новой Конституции СССР. Их знакомили с важными событиями международной и внутренней жизни, при этом особо подчеркивалась опасность для СССР империалистической агрессии. После упразднения национальных формирований, в связи с притоком на военную службу молодежи нерусской национальности было широко организовано обучение ее русскому языку, ознакомление с традициями и историей русского народа.

Великая Отечественная война явилась серьезным испытанием и в то же время показала огромное превентивное значение отечественной системы образования допризывной подготовки молодежи, гражданского, интернационального, патриотического воспитания населения. Система ликвидация неграмотности в тяжелые военные годы доказала свою крайнюю жизненную важность и необходимость в деле прямой защиты, укрепления и строительства государства. Это явилась важным фактором победы в Великой Отечественной войне.

\section{СПИСОК ЛИТЕРАТУРЫ:}

1. Иовлев А.М. Деятельность КПСС по подготовке военных кадров. М.: Воениздат, 1976. 120 с.

2. Партийно-политическая работа в Вооруженных Силах СССР. Исторический очерк. М.: Воениздат, 1974. $366 \mathrm{c}$.

3. Петров Ю.П. Строительство политорганов, партийных и комсомольских организаций армии и флота. М.: Воениздат, 1968. 541 с.

4. Сувениров О.Ф. Коммунистическая партия организатор политического воспитания Красной Армии. М.: Наука, 1976. 286 с.

5. Вырвич А. Красная Армия в борьбе с неграмотностью. М.: Военная типография, 1925. 123 с.

6. Куманев В.А. Социализм и всенародная грамотность. Ликвидация массовой неграмотности в СССР. М.: Наука, 1967. 326 с. 
7. Клочков В.Ф. Роль Красной армии в ликвидации неграмотности и подготовке кадров для села в годы социалистического строительства // История СССР. 1980. № 3. С. 94-103.

8. Елисеева Н.Я. Просветительная деятельность органов советской власти в Красной армии :1918-1920 гг.: дис. ... канд. ист. наук. М., 2005. 204 с.

9. Филоненко Т.В. Ликвидация неграмотности в губерниях Центрального Черноземья России (19201927 гг.) / под ред. проф. А.В. Лосева. Воронеж: Воронежский государственный педагогический университет, $1999.116 \mathrm{c}$.

10. Попова О.Н. Культурно-просветительная работа в Красной Армии: 1918-1923 гг.: дис. ... канд ист. наук. Самара, 2009. 273 с.

11. Сайгин Н.И. Забытое слово «ликбез»... // Блокнот агитатора. 1967. № 7. С. 24-31.

12. Сайгин Н.И. Коммунистическая партия - организатор культурного строительства в первые годы Советской власти (По материалам Южного Урала): дис. ... канд. ист. наук. М., 1967. 257 с.

13. Государственный архив Оренбургской области (ГАОО). Ф. Р-459. ОП. 1. Д. 540.

14. Пять лет борьбы с неграмотностью: сб. статей, воспоминаний и материалов / под общ. ред. А.С. Курской и П.А. Сычева. М.: Долой неграмотность, 1925. $171 \mathrm{c.}$

15. Российский государственный архив социально-политической истории (РГАСПИ). Ф. 1. Оп. 60. Д. 462.

16. Центр документации новейшей истории Оренбургской области (ЦДНИ ОО). Ф 1. Оп. 1. Д. 390.

17. ЦДНИОО. Ф. 1 Оп. 1. Д. 393.

18. Корнилова И.М. Формирование системы высшего образования в национальных районах России (на материалах Поволжья): учеб. пособие. Элиста: Изд-во КГУ, 2008.92 с.

19. ЦДНИ ОО. Ф. 1. Оп. 1. Д. 627.

20. ЦДНИ ОО. Ф. 1. Оп. 1. Д. 628.
21. КПСС в резолюциях и решениях съездов, конференций и пленумов ЦК. 1898-1970. М.: Политиздат, 1984. В 15 т. Т. 4. 1926-1929. 575 с.

22. Государственный архив Оренбургской области (ГАОО). Ф.Р-193. Оп. 1. Д. 2.

23. Народное образование в СССР. Общеобразовательная школа: сб. документов. 1917-1973 гг. / сост. А.А. Абакумов, Н.П. Кузин, Ф.И. Пузырев, Л.Ф. Литвинов. М.: Педагогика, 1974. 558 с.

24. Павлова Л.В. Ликвидация неграмотности взрослого населения. 1897-1939 гг. (на материалах Оренбуржья). Оренбург: Изд-во ОГПУ, 2011. 208 с.

25. Рабоче-крестьянская Красная Армия [Электронный ресурс] / Сост. Д. Кин; Серия пособий политрукам к политуставу. Вып. 1. 1922 // http://rkka.ru/ docs/real/rkka/main.htm.

26. Павлова Л.В. Работа по обучению и воспитанию красноармейцев и допризывников как фактор повышения боеспособности Красной Армии накануне Великой Отечественной войны // Россия в Отечественных войнах. Четвертые всерос. историкокраеведческие чтения памяти профессора П.Е. Матвиевского: сб. статей. 5-6 апр. 2012 г. Оренбург: Издво ОГПУ, 2012. С. 218-220.

27. ЦДНИОО. Ф. 4. Оп. 1. Д. 20.

28. ЦДНИОО. Ф. 371. Оп. 1. Д. 451.

29. ЦДНИОО. Ф. 371. Оп. 1. Д. 458.

30. ЦДНИОО. Ф. 371. Оп. 2. Д. 56.

31. ЦДНИОО. Ф. 371. Оп. 1. Д. 682.

32. ЦДНИОО. Ф. 371. Оп. 2. Д. 17.

33. Павлова Л.В. Обучение и воспитание красноармейцев и допризывников в 1920-1930-х гг. (на материалах Оренбуржья) // Народы Южного Урала на страже Родины: материалы всерос. науч.-практ. конф., посвящ. 200-летию Отечественной войны 1812 г., 400-летию победы Народного ополчения К. Минина и Д. Пожарского, 1150-летию Российской государственности / под общ. ред. В.В. Амелина. Оренбург: Издательский центр ОГАУ, 2012. С. 275-281.

\title{
EDUCATIONAL AND CULTURAL-EDUCATIONAL WORK IN THE RED ARMY IN 1920S-1930S: THE ORENBURG REGION ON MATERIALS
}

(C) 2016

\author{
L.V. Petrich, candidate of historical sciences, associate professor of the Chair of History of Russia \\ Orenburg State Pedagogical University, Orenburg (Russia)
}

\begin{abstract}
The article is sanctified important aspect in eradicating illiteracy in the years of Soviet power - training soldiers and youth of premilitary age. From the state of literacy of the population category to a large extent dependent on the fighting capacity of the Red Army. Having analyzed the historical scientific literature on the subject, the conclusion is made that the topic under consideration was studied to date is not enough. It is noted that in its entirety the problem of improving the combat training of the Red Army stood in 1923, when she moved to a peacetime footing. At the same time it developed a decree the Central Executive Committee and the CPC to bring to mandatory classes in literacy of youth of premilitary age during the passage of pre-conscription military training. The paper revealed that in the late $1920 \mathrm{~s}$ - early $1930 \mathrm{~s}$. work on training soldiers and youth of premilitary age continued during the cultural campaign. It is indicated that the organization of training, considerable attention was paid to the content of educational material related to the political education of soldiers. The peculiarities, difficulties and shortcomings in the organization of work with the staff of the Red Army in Orenburg: low attendance of paragraph literacy, large dropout of them. The article concludes that the system of eradication of illiteracy in the difficult war years, has proven to be extremely vital importance and necessity in the case of direct protection, strengthening and building of the state. This was an important factor in the victory of the Great Patriotic War.

Keywords: Literacy; the Red Army; youth of premilitary age recruits; Red Army; illiterate; semi-literate; educational work; political classes; cultural excursion; paragraph literacy; military; educational attainment; political departments; commissions literacy; cultural and educational work; Orenburg.
\end{abstract}

